\title{
La Gazeta de Antropología: de la precariedad local al ciberespacio global
}

\author{
JOSÉ LUIS SOLANA RUIZ \\ Universidad de Jaén
}

\section{RESUMEN}

Gazeta de Antropologia es una de las primeras revistas que dan comienzo en España en la década fundacional de 1980. Aunque surgida en torno al núcleo de antropólogos universitarios de Granada, su temática no se reduce al ámbito local; pues, por el contrario, acoge con frecuencia trabajos de reflexión teórica general, con una visión comprometida del estudio antropológico. Desde 1998 es la primera, casi única y, desde luego, más usada y consolidada, publicación cibernética dedicada a la antropología cultural en nuestro país.

Palabras clave: Andalucía, Granada, Internet, Publicaciones Electrónicas, Antropología cultural.

\section{SUMMARY}

Gazeta de Antropologia is one of the few journals in Spain that appeared in the founding decade of the 1980s. Although started by anthropologists related to the University of Granada, its contents is not limited to local matters; it covers subjects of general theoretical interest as well, approached from a committed standpoint. In 1998, Gazeta became the first journal of cultural anthropology in Spain to make its contents available through the internet and, at present, is the electronic journal of anthropology par excellence in the country.

Key words: Andalusia, Granada, The Internet, Electronic Publications, Cultural Anthropology.

\section{ORÍGENES Y MOTIVACIONES DEL NACIMIENTO DE LA PUBLICACIÓN}

Granada, comienzos de la década de 1980. Un grupo de personas, la mayoría de ellas vinculadas a la Universidad, unidas por relaciones de amistad y por su interés hacia la antropología, constituyen la Asociación

RDTP, LVII, 1 (2002): 129-138 
Granadina de Antropología y se plantean sacar adelante el proyecto de disponer de una revista que, a modo de boletín de la asociación, pudiese difundir sus investigaciones y trabajos. Así nació, en 1981, la Gazeta de Antropología (en principio, sólo con depósito legal; a partir del número 7 cuenta con su actual ISSN: 0214-7564). Y lo hizo con la intención de contribuir a promover los estudios de antropología, por entonces todavía alejados de las aulas y de las instituciones académicas, y ello en el sentido más general de la disciplina, tanto en sus dimensiones más etnográficas, locales y tradicionales, como en sus aspectos más teóricos, cosmopolitas y modernos. Nacía también con las pretensiones de estimular la investigación y de alentar el intercambio científico con otros colegas, revistas y asociaciones afines. El respeto y la consideración, en modo alguno acríticos, que sus miembros fundadores mantenían hacia lo tradicional suscitó que se optase por escribir Gazeta con ' $\mathrm{z}$ ', dando al nombre un toque arcaizante. La idea era publicar un número al año, periodicidad que ha conseguido sostener y que mantiene en la actualidad.

Nació sin apoyos institucionales (hubo incluso organismos públicos que comprometieron subvenciones que nunca hicieron efectivas). Posteriormente, en el número 6, contó con la colaboración de la Dirección General del Patrimonio Cultural, de la Consejería de Cultura de la Junta de Andalucía. El número 8 recibió para su publicación una ayuda del Área de Cultura de la Excma. Diputación Provincial de Granada. Los volúmenes posteriores, dispusieron de una pequeña subvención de la Consejería de Educación y Ciencia de la Junta de Andalucía. La independencia de la Gazeta, celosamente salvaguardada, la ha alejado del favoritismo de los organismos oficiales.

En un contexto de marginalidad y desconocimiento de la disciplina por parte de las instituciones, costó - y siempre ha costado- mucho esfuerzo mantener el proyecto. "Los números publicados [señalaba el editorial del número 12] han ido saliendo adelante, a base de dedicación voluntaria y voluntarista, de tenacidad y de ilusión de un grupo reducido de personas para pedir colaboraciones de artículos, pordiosear financiación y llevar a cabo nosotros mismos todas las tareas de edición y distribución". Todos estos esfuerzos no fueron vanos, sino que han dado sus frutos y, así, continúa el editorial citado:

La Gazeta de Antropología mantuvo los primeros años, en Granada, una presencia de la disciplina, cuando ninguna institución ni la Universidad daba oportunidad para los estudios de antropología en Granada. Fue un oasis en el desierto. Sus páginas fueron tribuna para dar a conocer investigaciones que se llevaban a cabo, reflexiones teóricas o información. Bajo su sombra funcionó un seminario 


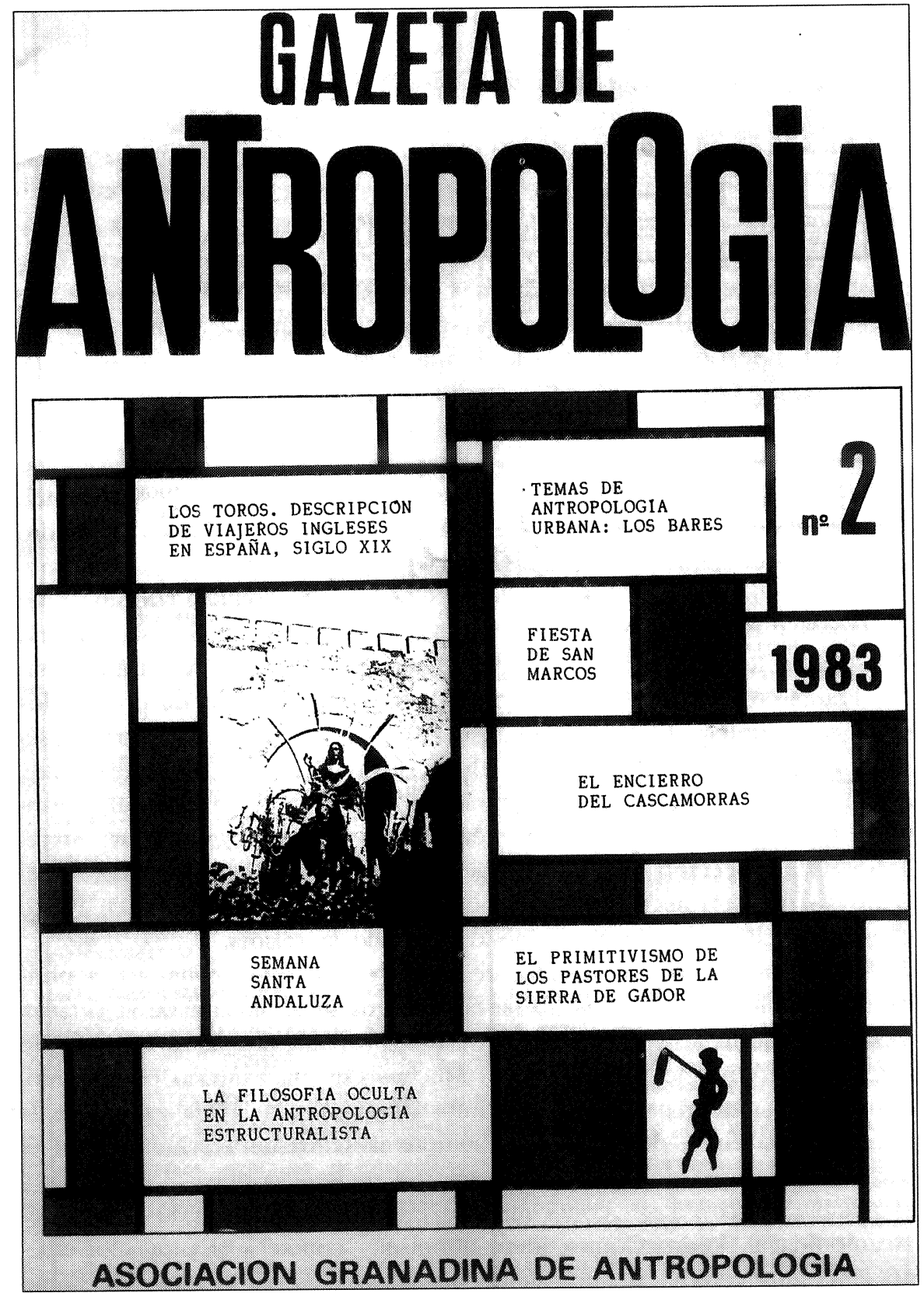


de antropología, grupos de investigación, algún congreso y diferentes ciclos de conferencias que dieron la oportunidad de oír y ver entre nosotros a algunos antropólogos de otras regiones de España y del extranjero.

\section{FORMATOS Y ORGANIGRAMAS}

Las catorce entregas de la Gazeta editadas en papel han mantenido siempre un formato tamaño folio. Los primeros seis números presentan una configuración artesanal. Sus páginas iban grapadas y la letra de impresión era Courier, tipo máquina de escribir. A partir del número 7, la revista adquiere una presentación más profesional. Aumenta su grosor, las páginas ya no están grapadas, sino cosidas; el canto es duro, también cambia el tipo de portada y la letra, que pasa ahora a ser modelo Times de imprenta. Como explicaré posteriormente, a partir del número 14 el formato es cibernético y digital.

En un principio, el Consejo de Dirección de la revista estuvo formado por Rafael Briones, Demetrio E. Brisset, Pedro Gómez y José Antonio González Alcantud. En el número 6, a este Consejo se sumará Alejandro Casado. En el número 9 se reorganiza el organigrama de dirección y redacción. Pedro Gómez y José Antonio González Alcantud aparecen como directores y Rafael Briones como Secretario de redacción. Se establece un Consejo de Redacción integrado por Demetrio E. Brisset, Alejandro Casado, Francisco Checa, Pedro Molina y Salvador Rodríguez Becerra (a los que en el número 12 se sumará José Luis Solana); y un Consejo de asesores constituido por María Jesús Buxó, Jesús Contreras, Enrique Luque, Antonio Mandly, Antonio Pérez, Fermín del Pino, Danielle Provansal y JeanRené Trochet. José Antonio González Alcantud dejó la revista para entregarse a la dirección del Centro de Investigaciones Etnológicas "Ángel Ganivet", por lo que a partir del número 11, de febrero de 1995, Pedro Gómez ejercerá en solitario como director de la misma.

Pedro Gómez, pues, ha sido, de modo colegiado o conjunto al principio e individualmente luego, y hasta el día de hoy, director de la Gazeta. Sería una injusticia no reconocer y dejar sin señalar que la revista pervive gracias a su empeño y buen hacer. Muchas personas hemos contribuido, en mayor o menor grado y en distintos momentos, a la realización de la Gazeta, pero él ha desempeñado siempre la labor imprescindible. De él partió la feliz idea de "cibernetizar" nuestra revista, lo que sólo ha sido y es posible merced a sus conocimientos informáticos, adquiridos de manera autodidacta. Pedro Gómez ideó, impulsó y concretó el proyecto, diseñó la página web y se encarga de actualizarla. Él es ejemplo de cómo entre la "cultura clásica" y la cibercultura no tiene por qué haber, como 
auguran los apocalípticos, antagonismo alguno, sino síntesis fructífera y mutuo enriquecimiento.

\section{TEMÁTICAS Y LÍNEAS PRINCIPALES DE TRABAJO}

Los temas tratados en los distintos artículos publicados en la revista han sido heterogéneos. Un significativo número de contribuciones se han ocupado de cuestiones de religiosidad popular, considerada ésta en sentido amplio, y de fiestas, tanto profanas como religiosas. En segundo lugar, cabría establecer un bloque constituido por artículos sobre las siguientes materias: estudios etnográficos sobre localidades, la mayoría de ellas de Andalucía; textos sobre cuestiones de claro carácter filosófico; contribuciones de temática americanista e indigenista; y artículos sobre teoría antropológica y antropología fundamental. Más allá de estos conjuntos temáticos generales, las cuestiones abordadas en los restantes artículos han sido muy diversas: relacionadas con expresiones artísticas y literarias (música, artes plásticas, literatura, cine), sobre la problemática de la identidad cultural, marginación, desigualdad, clases sociales, pobreza, gitanos, antropología urbana e industrial, métodos y técnicas de investigación, sexualidad, antropogerontología, antropología jurídica, drogas, globalización, e, incluso, artículos sobre Port Aventura o el orgasmo femenino.

En el editorial del número 13 (en el que, dicho sea de paso, se introdujo otra pequeña mejora: los abstracts o pequeños resúmenes en inglés de los artículos) se abogaba por actualizar los "objetos" de estudio de la antropología (algo que ha ido plasmándose en nuestra revista), lo que en modo alguno debe entenderse como un rechazo o un menosprecio hacia las temáticas y los campos de investigación antropológicos considerados como tradicionales, a los que la Gazeta siempre ha procurado y seguirá prestando acogida, sino como una reivindicación de la necesidad, por los fructíferos resultados que vienen obteniéndose, de que la antropología persista y profundice en el estudio de los fenómenos propios de las sociedades complejas. "Las investigaciones sobre los temas tradicionales - escribimos en el editorial- deben continuar, entre otras muchas razones porque el giro hacia una antropología de los mundos contemporáneos nunca podrá prescindir del estudio de esos otros mundos tradicionalmente estudiados por los antropólogos, pues, como magistralmente mostró Georges Balandier, para el estudio de la modernidad el desvío antropológico constituye un camino fecundo que llega a ser imprescindible.

Por lo que a los autores de los artículos se refiere, en la Gazeta han tenido cabida y acogida desde firmas consagradas, de renombre internacio- 
nal, hasta jóvenes desconocidos que iniciaban su andadura intelectual, pasando por profesores y profesionales de reconocido prestigio.

El editorial del número 10 señalaba como uno de los agrandes problemas aún no superados" de la revista "la ausencia de puntos comunes de debaten, añadiendo que ni siquiera la religiosidad popular, la temática más presente en los primeros diez números, los había suscitado. Pero, en mi opinión, esa falta de puntos comunes, si ciertamente confiere un carácter heteróclito y quizás excesivamente disperso a la revista, no obstante, desde otra perspectiva, ha posibilitado también algunas de sus virtudes: la variedad de temáticas abordadas en los artículos, la apertura de horizontes, esa sensación de plena libertad y de carencia de censuras o cortapisas que hemos sentido, y de la que seguimos gozando, quienes hemos publicado en ella.

No es, pues, la Gazeta una publicación temáticamente especializada. Pero detrás o debajo de sus variados contenidos, creo que pueden descubrirse talantes generales o vectores derivados, sobre todo, de los intereses y las relaciones personales e intelectuales de quienes, de un modo u otro, han contribuido y están contribuyendo a su progresivo desarrollo; líneas de orientación implícitas, nunca establecidas de modo explícito ni mucho menos impuestas.

En primer lugar, y como expresaba el editorial del número 3, puede constatarse una negativa a reducir la antropología a una "carrera", a "una tarea de especialistas"; una apuesta por entender la antropología como "una forma de mirar diferente de las demás ciencias del hombren. Mirada de amplios horizontes, capaz de integrar tanto las descripciones de carácter empírico como las reflexiones de naturaleza teórica, tanto lo etnográfico como lo filosófico, y motivada por la consciencia de la necesidad de ambos referentes polares y del bucle dialógico entre ambos atractores, aunque esto último haya quedado plasmado en menos artículos, entre otras razones por las mismas dificultades que entraña llevarlo a cabo.

Desde la Gazeta se ha intentado, además, potenciar análisis críticoemancipatorios orientados por ideales filantrópicos y procurando siempre que la crítica fuese juiciosa y fundamentada. A este respecto, en el editorial del número 13 se declaraba lo siguiente:

En tiempos de estupidización mediática, de pérdida de referentes teóricos sólidos, críticamente fundados (que no dogmáticamente asumidos), de adormecimiento de la consciencia, de triunfos del capital, de desmonte en un pis pas "democrático" (tiempos, sí, también, de pudrimiento de las grandes palabras) de conquistas sociales arrancadas con sangre tras luchas seculares, de retorno de formas de explotación laboral que parecían extinguidas..., en estos ensombrecidos tiempos 
finiseculares, la Antropología debe asumir de modo radical un hebermasiano interés crítico-emancipatorio.

Finalmente, quiero señalar también que, contraria al sectarismo y tenaz defensora del pluralismo ideológico, siempre que la ideología no falsee la realidad, desvirtúe el rigor ni merme la mínima calidad que todo trabajo intelectual debe lograr, la Gazeta ha mantenido, como planteamiento inspirador general, una resistencia a las explicaciones simplificadoras, reduccionistas y unidimensionales de los fenómenos y los procesos socioculturales. En esta línea, en el número 11 comenzaron a aparecer contribuciones sobre antropología compleja, resultado del estudio de la obra de Edgar Morin que algunos miembros del consejo de la revista, junto con sus doctorandos, preocupados e interesados en cuestiones de antropología general o fundamental y en epistemología de las ciencias humanas y sociales, venían desarrollando. De este modo, como señalé en el editorial del número 13, la Gazeta se sumaba a la apuesta por una antropología fundamental, inextricablemente vinculada a unos principios de intelección antirreduccionistas, a unos principios epistemológicos capaces de afrontar sin simplificar la complejidad de los fenómenos.

\section{PERSPECTIVAS ACTUALES Y DE FUTURO}

Octubre de 1998, número 14 de la Gazeta de Antropología: omega y alfa. Número fronterizo que marca el paso desde el papel a la red; número híbrido, pues fue publicado en papel, pero ampliado con contenidos (artículos, reseñas) nuevos en la red. Y es que nuestra revista abandona la tinta para convertirse en una publicación informatizada, digital, cibernética (esta transformación no afecta a su ISSN, que sigue siendo el mismo). A partir de ahora, los artículos, las reseñas y las traducciones de todos los números, desde el primero, son accesibles gratuitamente a través de la página en Internet de la Gazeta: http://www.ugr.es/local/pwlac. Esta página está vinculada al grupo de investigación del Laboratorio de Antropología Cultural (Departamento de Filosofía de la Universidad de Granada) y, además, incluye la normativa para publicar en la revista, indicaciones para realizar canjes y pedidos, enlaces a otras páginas y a otras revistas de antropología y ciencias Sociales en general, y una normativa internacional (ISO 690-2) sobre citas electrónicas.

En el editorial del número referido — que parafraseo en lo que siguese informaba de la mudanza a Internet. Como sabemos, hasta entonces la Gazeta había venido publicando sus números convencionalmente im- 
presos en papel. Pero los tiempos cambian, y las nuevas tecnologías informáticas, con su sencillez de manejo, su bajo costo económico y su alcance mundial, han revolucionando en breve tiempo las posibilidades de comunicación, abriendo nuevas vías de intercambio científico e intelectual. En Internet, la mejor editorial y distribuidora del planeta, y merced a la red de la Universidad de Granada, la Gazeta encuentra el mecenas que nunca llegó a tener, el medio que le permite eludir las trabas económicas que desde sus inicios la han acuciado.

El modo de publicación de la revista deja de ser puntual (todos los artículos se publicaban conjuntamente al mismo tiempo) para pasar a ser procesual: cada año se abre el número en curso, que se mantiene así a lo largo de sus doce meses, y los artículos se van publicando conforme van llegando y se les otorga el visto bueno. Al final del año, se cierra el número y se hace una edición en soporte CD-ROM, que no sólo incluye los contenidos del número anual correspondiente, sino los de todos los números anteriores de la Gazeta, es decir, la colección entera de la revista. El cederróm, que incorpora un programa para la lectura y consulta de los documentos, se utiliza para mantener los intercambios con otras revista y se remite, previo pago de un módico precio, a las personas e instituciones que lo solicitan.

Las ventajas del nuevo y revolucionario formato son muchas; entre otras: es más económico; el espacio (el "número de páginas") es casi ilimitado (lo que ha permitido en el último número, constituido por 26 artículos, triplicar prácticamente la extensión del contenido de nuestra revista con respecto a lo que podíamos cuando se editaba en papel. 7 artículos incluía el primer número, y unos 10 ha sido la media de los restantes). La difusión es internacional, cualquier persona, desde cualquier lugar y en cualquier momento, puede, mientras goce de acceso a Internet, servirse de nuestra revista. Supone un ahorro, tanto para nosotros (no hay costos de impresión ni de envío por correo), como para los lectores, quienes ya no tienen por qué comprar una revista entera cuando, como suele ser normal, sólo les interesan y leen algunos artículos; ahora pueden imprimir o "bajarse" y archivar los artículos que deseen.

Según las estadísticas del contador Nedstat (incorporado a la página), desde el septiembre de 1998 hasta hoy (abril de 2001) ha habido más de 35.000 visitas. Rondamos ya las 80 visualizaciones al día, con algunos días en los que se ha superado el centenar. Un 30\% de las visitas proceden de España y el resto de más de 60 países (destacando México, Argentina, Estados Unidos, Chile, Colombia, Perú, Brasil, Portugal, Francia...; incluso desde el FBI nos han realizado alguna visitilla), lo que es clara muestra de la enorme difusión internacional que a través de la red puede alcanzar una revista, un claro ejemplo de cómo lo local se globaliza. 
En este nuevo período hay varios proyectos que intentaremos cuajar, a los que paso a referirme brevemente.

Cuando nuestra revista era menos conocida y la edición en papel circunscribía a un número determinado, limitado e irrebasable de páginas, la selección de los artículos apenas planteaba problemas. Pero hoy, con la consolidación de la Gazeta en el ámbito nacional y con la mayor difusión que gracias a Internet tiene en el plano internacional, nos están llegando muchos textos de personas a quienes no se los hemos solicitado y que, en muchos casos, nos son desconocidas. Ahora, el espacio, el número de páginas, ya no es argumento para excluir un artículo. La capacidad casi infinita que el soporte electrónico otorga nos permitiría difundir prácticamente todo lo que nos llega. Ante este hecho, se hace más necesario aún disponer de un Consejo de Redacción operativo que filtre las muchas y dispares contribuciones que recibimos. Este es uno de los retos futuros de nuestra revista, con el fin de elevar la calidad, en nuestra opinión ya bastante aceptable, de los artículos que se publiquen en ella.

La traducción de artículos de calidad y, en especial, de textos "clásicos" o "de clásicos" aún no vertidos al castellano, junto con una sección de reseñas y recensiones amplia y actualizada, son otros dos retos pendientes. Fue en el número 11 cuando comenzamos a intentar desarrollar dicha sección; este número incluye ya 4 recensiones, y, con logros dispares, en los números posteriores nos hemos esforzamos por incrementarlas (el número 13 contará con 6), lo que, en honor a la verdad, sólo hemos ido logrando en parte. Conseguir una buena sección de reseñas y recensiones sigue siendo un reto pendiente, no fácil de lograr.

Finalmente, barajamos también la posibilidad de introducir cada año, como ya se ha hecho en el número del 2000 , monográficos temáticos, que serían encargados a alguna persona, quien actuaría como coordinador.

La Gazeta de Antropología está indexada en la base de datos ISOC, del Consejo Superior de Investigaciones Científicas (Madrid). En Internet, se encuentran enlaces permanentes hacia la página de la Gazeta desde las páginas de importantes universidades de Estados Unidos, Inglaterra, Francia, Suiza, Italia y de los países latinoamericanos; también desde diferentes universidades españolas, desde sitios especializados en antropología y desde los más prestigiosos buscadores y catálogos temáticos digitales. Se le ha otorgado el certificado de calidad dobleU.com, "por cumplir con excelentes estándares de calidad en su contenido, diseño, originalidad y claridad en la presentación de la página”. Y está considerada, al día de hoy, según estimación de la web especializada El Rincón del Antropólogo (www.elrincondelantropologo.com) como uno de los diez mejores lugares de antropología iberoamericana en la red. 